\title{
Reliving the Partition in Eastern India: Memories of and Memoirs by Women across the Borders
}

\author{
Sharmistha Chatterjee Sriwastav \\ Associate Professor, Department of English, Aliah University, City Campus, West Bengal, \\ India. ORCID: oooo-ooo1-6771-0435. Email Id:dr.s.c.sriwastav@gmail.com
}

\begin{abstract}
Genocide in Bangladesh:1971 (2015), edited by A.K.M Nasimul Kamal is a well- documented, organised and factual record of newspaper clippings from all over the world. A collective effort, it is an objective, yet horrific account of the brutal atrocities of West Pakistanis on the Bengalis in East Pakistan, carefully interspersed with the international politics behind it. Compared to this unparalleled book and many others like this, memoirs by individual women recording the carnage during the Bangladesh Liberation Struggle are pale, unreliable and flickering comments on the events and the real politick behind the bloodbath. Yet as the paper argues, these memoirs and interviews by various women, from all walks of life, do create an alternative history- a history characterised and problematised by doubts, gaps, lapses, silences, turbulences and half realized truths.

Autobiographical accounts by Begum Mushtari Shafi (translated, 2006),cand Farida Huq (2008), former a social activist and latter an educationist coupled with interviews given by several ordinary, poor women across the borders ( recorded in 2009) demand closer attention to themselves by recreating the gruesome days. Falling back on their personal repertoire which oscillates between the home and the world, these largely anecdotal narratives fill in the void of homogeneous official records. These memoirs do retrieve how women acted or were acted upon in the devastation which changed their lives permanently.
\end{abstract}

Keywords: Partition, Women, Eastern India, Memories, Memoirs, alternative, history, lapses, void.

\section{Introduction}

The Partition of Bengal and the Bangladesh Liberation War has evoked interest among the critics much later than the divide of the subcontinent in the North- West, commonly referred to as Punjab Partition. Tendencies to trace the divide of Bengal among communal lines, has also been reiterated, thus building a narrative which is congruent and the other half of the Punjab Partition. Official documents trace the violence as a result of Hindu- Muslim animosity with women bearing the brunt of the holocaust by being raped, assaulted or abducted. The Partition of Bengal in 1947 which provoked a massive exodus of the minorities across the border is however different from that experienced in Punjab in at least two important ways. Firstly, in Punjab the exodus was a two-way process leading more or less, to the exchange of minority populations. And secondly, whereas in Punjab the migration was accomplished in one fell swoop, that is within a brief period (1947 to 1950), in the east the migration from 'East Bengal' first and later from 'East Pakistan' and 'Bangladesh' has continued till this day.

The causes are other than communal skirmishes, which is always not the primary reason. Beyond 1971 which resulted in the creation of Bangladesh, the micro-narratives of individuals (especially women) trace other practical causes of leaving the eastern or western half of Bengal. Women and their narratives conjure a separate world of active decision making and an effort to

(c) AesthetixMS 2020. This Open Access article is published under a Creative Commons Attribution Non-Commercial 4.0 International License (http://creativecommons.org/licenses/by-nc/4.0/), which permits non-commercial re-use, distribution, and reproduction in any medium, provided the original work is properly cited. For citation use the DOI. For commercial re-use, please contact editor@rupkatha.com. 
empower selves. Such micro-narratives certainly develop an alternative discourse and a better fate of women caught in the crosscurrents of Bengal Partition and Bangladesh Liberation War.

Accounts of women from the field endorse this protracted nature of Partition in the East of the sub-continent and emphasise the agential role of women countering the very deadening effect of the holocaust and its aftermath.

The account of Shikha Halder (Bengali, Hindu), aged in her own estimate 45, who had crossed over to Duttaphulia in Ranaghat, India in the year 1994 from Chowgacha, District Jessore in Bangladesh is one of the many cases to lend credulity to the fact that the migration post Bangladesh Liberation War, is far from ceasing.

Fleeing with two young Children and one unborn (in the womb) at the time of migration, Shikha is a classic case of the perpetual movement of people across in borders of India and Bangladesh even after 60 years of the epoch making partition which divided the subcontinent into India and Pakistan and later on Bangladesh.

At present Shikha Halder works as a domestic help in upper middle class houses in Barrackpore, a suburb in North 24 Parganas in West Bengal India.She has about 5 years ago managed to wade over the crisis of the status of a 'refugee' by being able to procure a voter and a ration card - markers of authentic citizenship in post-partition India. All this is good when understood in the context of present vote bank politics, but Shikha's and many other's accounts do reveal several other startling facts, which have made scholars and historians rethink, reread, the process and the continued impact of partition in South Asia.

On being asked about her memories of the Bangladesh Liberation War in 1971,Shikha like many other illiterate women (in the interviews recorded in Bagchi and Dasgupta's, The Trauma and the Triumph, Vol. 2) failed to recollect specific details of any communal violence in her village in erstwhile East Bengal, but she was able to remember vaguely some temples being burnt down.

And then like others,(Sunanda Ghosh, Naseema Dey, Nazara Huq) she blurted out almost with visible inconsistency that she must have been 20 then (putting me as an interviewer to grope in darkness about her real age, since she claimed she was 45 at the time of the interview [20.06.2016]). As an interviewee she reverted and emphasized that the reason of her exodus, like many others, was not because of the subtle discrimination that she met as a Hindu in a Muslim majority Bangladesh, but the need to be economically self reliant in a neighbouring country which seemed to have resources and space for everyone. Thereby reiterating the claim of Haimanti Roy, a well- known historian that onslaught of refugees and movements across the borders continue happening due to 'economic reasons' than communal ones. ${ }^{1}$

Shikha Halder seems to have paid Bangladeshi Police a paltry sum of Rs. 100 to cross over to the Indian side, which again turns the tables on politicians and nationalists who claim that the issue of partition has been resolved in Eastern India with the creation of Bangladesh in 1971 and that the refugee crisis in a matter of the past.

Shikha Halder wants to stay back in India but her heart yearns for the brothers who remain in Jhigorgaacha Bangladesh. Halder's passport has been denied in India because she could not produce her mother's death certificate (her mother had died in her infancy). Shikha fondly remembers her Muslim neighbours and would like to meet them. 


\section{Rationale and patterns of women's migration in the East}

In this context, the experience of Assam offers an interesting comparison. Whereas in West Bengal the migrants are mostly Hindus, in Assam the migrants from East Pakistan and Bangladesh were mostly Muslims. ${ }^{2}$ This factual evidence is consolidated by citing the memoir of Begum Mushtari Shafi who fled 'East Pakistan' on the eve of its liberation as Bangladesh in 1971. In her and the case of her contemporaries, Assam became the temporary corridor, through which many East Pakistani Muslims later on reached Kolkata.

Bagchi and Dasgupta's (2009), comment conclude on the basis of records that "Hindu migrants were prompted by a feeling of fear and experience of persecution either committed or threatened, the Muslim migrants who crossed over to Assam were primarily by economic considerations" (Intro xiv)

Bagchi and Dasgupta's observations might be true, but is relevant only to the process of migrations that occurred into India till April 1958. Migrants who came in the later years i.e. between December 1963 to the late 1970 and beyond, were motivated by financial incentives than anything else, as has already been explained in the interview by Shikha Halder.

Archit Basu Guha Chaudhury records the opinions of East Bengali Migrant women moving towards self-liberation in the process of supplementing financial positions for the family. Though (as Guha Choudhury opines) women had to bear the brunt of discrimination on the basis of their gender because they were made to believe that the economic domination of the male was a preordained state, they did realize their freedom. Namita Roy Chowdhury who was a victim of economic necessity after her father's death, says on the issue: "Takhn amra baritikhe baire giyechilam takhan amader poribar amar samsar chilo kintu baire javar pore aamra nijer sansar chilam" ("when we went out to work initially, our family was out world but after we started working, we realised we were our own world"). ${ }^{3}$

Namita's observation rings true not only in case of Hindu women migrants to India from 1960 s onwards to the present, but also Muslim women who moved in largest number to India permanently or temporarily during the Bangladesh Liberation was in 1971. In her memoir Days of My Bleeding Heart (trans. A. S. Mondle) Begum Mushtari Shafi writes, (in the same strain as Halder) "I don't know politics, I do not understand politics, yet I felt perhaps things were not quite right." (104)

But also, while in the refugee camp in Agartala, "I am not involved in any work now, just roaming about without work, but I want to keep myself busy... From today I started distributing milk powder, recording in the master roll Mr. Saha gave me the recipient's name, age, quantity of milk powder issued." (216)

In return Shafi was given a small remuneration by the Red Cross.

Exodus of migrants from East Pakistan did happen stealthily but continuously in absence of any large scale border violence in Eastern frontiers, but the most notable years were 1946 (during the Noakhali riots), 1950 and ultimately in 1971, where the proverbial violence, anarchy and exodus associated with the $1^{\text {st }}$ partition was relived. Interestingly historian Pran Chopra chooses to call the Bangladesh liberation war as India's Second Liberation. ${ }^{4}$

\section{Liberation war and Indo-Pak relations: macro and micro narratives}


Official records as in Moidul Hasan's Muldhara Ekattor or A.K.M. Nasimul Kamal's Genocide in Bangladesh 1971, do acknowledge the tremendous pressure of refugees in West Bengal during the period, the inevitability of the necessity of India's intervention and the subsequent impact of the war on Indo-Pak relations.

Hasan records the report of New York Times, October 10, 71:

With refugee population swollen to 9 million, West Bengal was in an explosive condition... Tensions are fastening both inside and outside the refugee camps. And the temptation to get rid of the crushing burden by intervening in the fighting meant another war with Pakistan[...] (95)

Similarly, Kamal under the heading "Unbalanced Exchange" records the news in TimesMagazine, June 21, 1971:

While India has temporarily accepted the refugees and is doing its best to help them, the government of Indira Gandhi sees only economic and political disaster in the massive influx of the impoverished people... since partition 4,300,00o Hindus from East Pakistan have fled to India, for most part into West Bengal... The food required by the refugees is rapidly depleting existing food stock piles and threatens to create a famine for the Indian themselves. The refugees are also taking work away from the Indians, In West Bengal the refugee peasants are hiring out as agricultural labourer for a quarter of the wages local labourer is paid. (252-253)

In contrast to such statistics and facts, Farida Huq's and Mushtari Shafi's memoirs typically present themselves as counter narratives, challenging Kamal's, Hasan's and therefore,New York Times' propaganda of aggression, crisis and communal disharmony. Crisis is indicated definitely, but it is more because of the atrocities of West Pakistani's on the Bengalis. In the women's narratives there is an appreciation of India's timely aid and there are prayers for India's win.

Soon India recognized Bangladesh as an independent country.[...] We rushed upstairs to the roof, to see the Indian Air Force planes in action, we heralding them as our saviours.[...]

My brothers were extremely excited at the outcome of everything I hoped they did not do anything stupid and create problems for everybody. As the war escalated, our hopes and aspirations soared to the greatest heights, we prayed for India to win. (182-183 Dec 3-16, My Story)

That, in the liberation of East Pakistan as a nation and its survival the ultimate onus was on India, is definitely indicated by the startling revelation of Huq as a prisoner of war of West Pakistan from the concentration camps in Quetta:

Just a year ago December 16, 1971, Bangladesh became a reality, since then we've been waiting frantically to go home. Instead of 'homeward bound', today we're bound for the 'concentration camp'! The 'Pakistanis', failing to take their ignominious defeat in good grace, take it out on us - the innocent stranded Bengalis pawns in their hands! (231 Dec 23, 1972, My Story)

No official documents do record that the Bangladeshis (and their families) who served as officers in the Pakistani Army (like Farida Huq's husband) were taken as prisoners of war and sent to concentration camps, waiting to be released when India releases the Pakistani POW on this side of the war. Huq's memoirs have far reaching impacts in shaping the history of the sub-continent, since 
her observations are framed on the basis of her experiences in both Bangladesh and Pakistan during the year of the Bangladeshi war and its immediate years of aftermath,(1971-1972), bringing out the crucial role of Indian government and the army along with the 'muktijoddhas' in the ultimate days of nation building.

Huq's revelations further interrogate the assumptions of the historians, that only the Eastern frontier was challenged in the year 1971, because there were many Bengali Muslims who waited to return to India from the North too (Pakistan):"He (Huq's father) narrated the miserable plight of the hundreds of Bengali's stranded at Kabul, waiting for air tickets for India." (213 May 8, 1972 - December 23, 1972)

\section{Communal harmony among Bengalis and role of women}

While Kamal's newspaper records emphasize the competitive spirit between the East Bengalis and the West Bengalis, Begum Mushtari Shafi's version as a fugitive and a subsequent refugee in Kolkata, serves to unearth their opposite.

Ma, you all appear to be too tired, take rest at our place for a few days, let me cook some rice for you. Between that Hindu fisherman's wife and ourselves there wasn't a wall of religion today, a turbulent awakened feelings of nationalism has madeus having but one and the same soul. Our main identity now - we are Bengalis. We are now awakened. (147 Days of MyBleeding Heart)

And:

We were awestruck having gone to a Puja pavilion in Dharmatala (Kolkata). The entrance was decorated with stratified images of the division of India in 1947. It started from Gandhiji, Jinnah and Jawaharlal Nehru; the process of handing over of the government; depicting language movement, Sheikh Mujib, Ayub Khan, Mass Movement, Yahia Khan, Bangladesh War, Bangladesh Cabinet. At last, in place of Durga there was an image of Indira Gandhi with Yahia Khan lying demon at her feet. At this spot Sheikh Mujib's speech and patriotic songs were being played [...] $\left(311,19^{\text {th }}\right.$ October)

(There was) genuine compassion and sincerity of the local people towards us. In the train, bus, shops, markets wherever we went if others come to know we were from Bangladesh, they would show so much of respect and sympathy, we felt an intimate attachment with them since, although the people speaking the same language were divided resulting from division of a country, we have still remained as children begotten of the same mother, meeting after a long period of time." (283- $28421^{\text {st }}$ September, $D$ of $\left.M B H\right)$

Shafi's accounts might be emotional, might lack statistics, but nevertheless are crucial to fill in the gaps, left gaping, by the official records. Unlike Hasan (a very important Government official) or Kamal, an observer from East Pakistan, Shafi's direct involvement with the war just like Huq, manifests the common women's experience and reality. Interestingly, West Bengali's spontaneous response to the 1971 war, could be rationalized in the words of Partha Chatterjee: "(In case of undivided Bengal) The Bilingual intelligentsia came to think of its own language as belonging to(the) inner domain of cultural identity, from which the colonial intruder had to be kept out; 
language therefore became a zone over which the nation first had to declare its sovereignty and then had to transform in order to make it adequate for the modern world." (6) 5

Joya Chatterjee (2007), also detects that certain accidents of human and environmental history produced a certain cohesiveness in the region. Various factors, including agriculture and trade in the modern times had forged connection between different parts of Bengal, "knitting together their local economies into a larger whole. By modern times, the delta had come to share ways of life based on the cultivation of rice and a vernacular which, despite its local variants, was coming to be the lingua franca of the region as a whole." (Intro 5 Spoils of Partition). Historically, by the end of the nineteenth century, Muslims outnumbered Hindus in Bengal (undivided) as a whole and then become an overwhelming majority in its eastern tracts. But, Chatterjee notes that, "most of Bengal's Muslims were humble peasants whose beliefs and practices continued to have more in common with local cults than with the Islamic orthodoxies and courtly cultures of northern India." (6) Historians, also trace the initiative of the Bengal partition in 1947 to be of interest, more, to the Hindu upper castes than the Muslims who were on the contrary reluctant to join West Pakistan. ${ }^{6}$

It is therefore no surprise that the Memoirs of Shafi or Huq should trace fellow feelings among the Bengali's of the two sides with shared emotions for 'Rabindra' and 'NazrulGeeti' as a part of a common language and culture. In contrast to Kamal's exposition of only atrocities on women during 1971, Shafi's and Huq's narratives show a distinct women's (in the words of Elaine Showalter) 'sub-culture'. Shafi's memoirs elucidate the contributions of women of both the Bengals at 'Swadhin Bangla Betar' (roughly to be translated as, Independent Bengal Radio) to spread awareness of the need to stop genocide in Bangladesh which includes her own contribution as a script writer to depict the condition of women in Bangladesh war.7Shafi's, accounts add a dimension to the women participating in the 1971 war, the role of culture and arts of the East and West Bengal to appeal to the good sense of the world, "Mini returned in the evening with two cards of a cultural function being presented by 'Epar Bangla-Opar Bangla Shilpi Parishad' (The Council of Artists of both Bengal) tomorrow evening in Kalamandir Hall. Mini said, 'This is a charity show to help the Bangladeshi artists and refugees."' (300)

Harrington, in his well- researched article, "Women and Resistance in West Bengal and Bangladesh: 1967-1971", had discussed the contribution through the mode of transgressive action, of militant women in Bangladesh Liberation war in 1971. These militant women were referred to as 'birangonas' in the Bangladeshi war and Naxalite movement India. Harrington cites examples from the English translations of two short stories, the first "Double war" by Selina Hossain and the other, "Draupadi" by Mahasweta Devi. Similarly, retaliation of ordinary women even after sexual exploitation to challenge the 'rajakars' has also been the subject of Jahanara Imam's stories. ${ }^{8}$

\section{Dreams vis-a-vis Reality}

However, Shafis and Huq's memoirs do not talk about such mythical and superhuman bravery, yet they do rescript history by including continuous currents of information where women have been (albeit) peripherally instrumental in saving, nursing, rehabilitating, protecting (encouraging) other women and men during the long years of crisis, "Sitting on Charpais or on carton boxes - the nostalgia too painful to bear, we burst into singing. I invite Rosy, Helen and Koeli to sing Tagore's 'Kothao Amar Hariye Jawar Nei Mana, Mone Mone... and end up singing 'Amar Sonar Bangla Ami Tomai Bhalobashi, My Golden Bangla we love you' ... Adept in camp life, we lead a novel indigenous life of hardship, sharing our hopes and despair together! [...]" (267 Huq March 1973) 
Begum Shafi's memoirs end on $20^{\text {th }}$ January 1972 , when she returns to Dhaka from Kolkata after having lost her brother and husband in the Liberation war. Farida Huq's travails continued longer, as prisoners of war, they were allowed to go back to Bangladesh en-route India on November $29^{\text {th }}, 1973$. Fortunately, she had her family intact.

Kamal's official records too cease with Newsweek, January 24, 1972 when Sheikh Mujib took over as the president of joyous Bangladesh. The book is careful to include the prospects of a new nation and in its last pages and significantly includes expert's opinions as the following:

One of the main conditions of India's support is that Bangladesh organise the expeditious return of the refugees and restore their lands and belongings to them. The Bangladesh government is also intent on seeking war reparations from Pakistan if possible. (471)

However like Shikha Halder, Sunanda Ghosh , originally from East Bengal has not returned back home. She continues to live in a refugee colony in Jamshedpur, Bihar (India). Nazara Huq, an Indian,(Shibpur, West Bengal) who had migrated to Dhaka considered crossing the borders again in 1971 to Calcutta , but did not - However she is still considered a migrant and does not have any property in Bangladesh. There are other women,NaseemaDey and KishwarJahan who still rue the partition of Bengal and others like Taiyeba Ahmed who still regret crossing over to East Bengal with nostalgic memories of Kolkata. ${ }^{9}$

\section{Conclusion}

The memories and the memoirs of these women only serve to protract and complicate a discourse seemingly to have ended in 1971 with the creation of Bangladesh as a new nation. Citizenship of 'illegal migrants' like Shikha Halder who have come from Bangladesh "have been extremely politicized and linked to Hindu right wing movements[...]Although the xenophobia towards illegal Bangladeshi migrant is of recent vintage. They find their roots within post-partition politics surrounding the citizenship of migrants and the porosity of the Bengal border." (Roy Epilogue 223) Again, "Subsequent politics of Bangladeshi vs Bengali national identity have covertly and overtly privileged a Muslim citizenship in Bangladesh." (223). In such discourses, the non-Muslims find limited space.

In spite of such government policies and skewed perspectives, it is true that it is still difficult to determine the identity and citizenship of these South-Asians who are so linguistically and ethnically similar and bear little or no marks of their religious denominations.

\section{Notes}

${ }^{1}$ Roy, writes in her book Partitioned Lives: Migrants, Refugees, Citizens in India and Pakistan, 1947-1965 (2012), " [...] there has been a tradition of migration from rural Eastern Bengal to urban centres of West Bengal, mainly Calcutta, to obtain higher education or work. Although partition divided this region into two new states, such patterns of temporary migration and divided families continued within existing networks of kinship relations and economic associations [...]" (98).

${ }^{2}$ Details of this information to be had of Bagchi, Dasgupta and Ghosh edited, The Trauma and the Triumph: Gender and Partition in Eastern India. (Vol-2). 
3 From Archit Basu Guha Choudhary's “Engendered Freedom: Partition and East Bengali Migrant Women”, Economic and Political Weekly, Vol. 44, No. 49 (December - 11, 2009), PP. 66-99.

${ }^{4}$ Pran Chopra's comments and opinions on the Bangladesh Liberation war (1971) is recorded in Hasan, Moidul. Muldhara, Ekattor. Dhaka: The University Press Limited, 2013. The book to be referred to is,Pran Chopra, India's Second Liberation ( Delhi: Vikas Publishers, 1973)

5The excerpt is taken from Partha Chatterjee's article, "Whose Imagined Community? “ in Sekhar Bandopadhyay edited Nationalist Movement in India.

${ }^{6} J o y a$ Chatterjee writes, "In these ways, for a fateful moment in 1947, Delhi's purposes dovetailed fortuitously but neatly with the plans of those Hindus in Bengal their province. This chance conjuncture gave the Hindus of Bengal what they were after the partition of their province and a Hindu dominated, albeit truncated, state of West Bengal." (Intro 15)

7The exact words of Begum Mushtari Shafiare, "I also wrote for Swadhin Bangla Betar another sketch entitled 'Women in Bangladesh War'." (301, Days of My Bleeding Heart)

${ }^{8}$ Harrington, Louise. "Women and Resistance in West Bengal and Bangladesh : 1967- 1971," JPCS Vol.4, No.2, 2013 , p. 57.

9Information to be had of Bagchi, J., Dasgupta, S. and Ghosh, S. edited, The Trauma and the Triumph: Gender and Partition in Eastern India, Vol2 . Kolkata: Stree, 2009.

\section{References}

Bagchi, J. Dasgupta,S \& Ghosh, S. (Eds). (2009). The Trauma and the Triumph: Gender and Partition in Eastern India, Vol 2. Kolkata: Stree.

Basu Guha Choudhary, Archit. (2009). "Engendered Freedom: Partition and East Bengali Migrant Women.” Economic and Political Weekly, 44 (49), 66-99. Retrieved from http://www.jstor.org/stable25663863.

Chatterjee, Joya. (2007). Spoils of Partition. Cambridge: C.U.P.

Chatterjee, Partha. (2009)."Whose Imagined Community?” Nationalist Movement in India. Ed. Sekhar Bandopadhyay. New Delhi: Oxford University Press.

Harrington, Louise. (2013). "Women and Resistance in West Bengal and Bangladesh: 1967- 1971." The Journal of Post-Colonial Cultures and Societies, 4 (2), 47-79. Retrieved from http://www.jpcs.in/upload/514931101Harrington.pdf.

Hasan, Moidul (2013). Muldhara, 71. Dhaka: The University Press Limited.

Huq, Farida. (2008). Journey through 1971: My Story. $2^{\text {nd }}$ edition. Dhaka: Academic Press and publishers Library.

Kamal, A.K.M, Nasimul. (Ed). (2015). Genocide in Bangladesh 1971. Dhaka: Banglaprakash.

Mushtari Shafi, Begum. (2010). Days of my Bleeding Heart. Trans. A.S. Mondle. Dhaka: Mowla Brothers.

Roy, Haimanti. (2012) Partitioned Lives: Migrants, Refugees, Citizens in India and Pakistan, 1947-1965. New Delhi: O.U.P.

Author's bio-note: Dr. Sharmistha Chatterjee Sriwastav (M.A., Ph.D, B.T, P.G.D.T.E.) is Associate Professor at the Department of English in Aliah University, Kolkata, West Bengal. Her doctoral thesis is on Indian Poetry in English. 